\title{
Photosensitivity Characteristics of UV Curable Organic-Inorganic Hybrids Sensitized with Benzoin Derivatives as Photobase Generators
}

\author{
Nobuhiro Ishikawa, Koji Arimitsu*, Masahiro Furutani, \\ Takahiro Gunji, and Yoshimoto Abe
}

\author{
Department of Pure and Applied Chemistry, Faculty of Science and Technology, \\ Tokyo University of Science, 2641 Yamazaki, Noda, Chiba 278-8510, Japan
}

Keywords : photobase generator, UV curing, benzoin derivertive, organic-inorganic hybrid

\section{Introduction}

Most of the photo crosslinkable materials are based on photoradical polymerization and photocationic polymerization. The technologies are widely used in resists [1], coatings [2], printings [3], adhesions [4] and so on because many photoradical and photoacid generators (PAGs), monomers, and oligomers are commercially available. On the other hand, the reports of photobase generators (PBGs) are rare when compared with PAGs because of their low quantum yields and relatively low basicity of generated bases. Anionic UV curing is an excellent method because it is free from polymerization inhibition by oxygen, termination by water, corrosion of metal substrates, and volume shrinkage. Until now, several researchers have reported PBGs and demonstrated the advantages of PBGs in the field of photolithography [5-11]. The improvement of the quantum yield for photobase generation and of the basicity of photogenerated bases is strongly needed. Recently, we have reported photoreactive carboxylates comprising ketoprofen and superbases as novel PBGs, which undergo photodecarboxylation to generate free superbases with high quantum yields [12]. A novel anionic UV curing system sensitized with the photo-superbase generator is under investigation. On the other hand, aliphatic amines as a weak base are useful to prepare organic-inorganic coating films. For example, photo-generated aliphatic amines cause addition reactions toward epoxy groups and catalyze sol-gel reactions of metal alkoxides, leading to highly cross-linked materials [13]. Although hybrid UV-curing systems based on radical and cationic polymerization were reported [14], analogous systems based on radical and anionic polymerization have never been reported. If there are PBGs that generate amine and radical simultaneously, the PBGs should act as an effective photoinitiator to prepare organic-inorganic hybrid coatings from acrylate monomers or oligomers with alkoxysilyl groups.

Based on this idea, we have reported novel PBG 1 with benzoin units that generate secondary amine and radical species [15]. We report here photosensitivity characteristics of UV curable organic-inorganic materials sensitized with novel

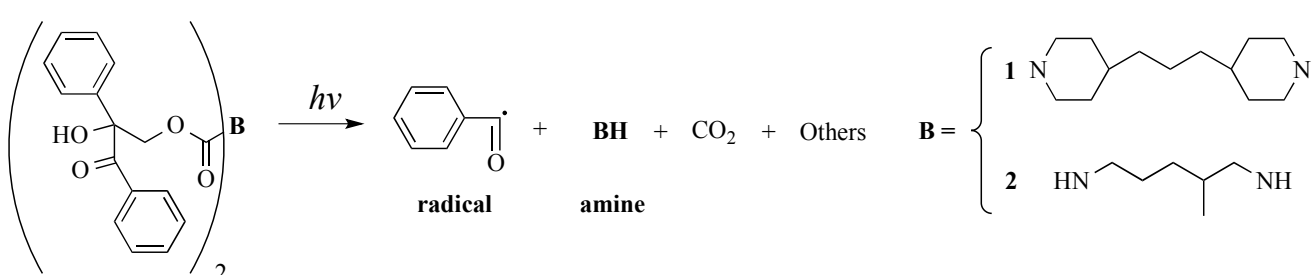

Scheme 1. Photoinduced generation of aliphatic amine and radical from photobase generators $\mathbf{1}$ and 2 
PBG 2 with benzoin units that generates radical and primary amine simultaneously by photo irradiation (Scheme 1).

\section{Experimental}

\section{1. Materials}

\section{Synthesis of PBG 2}

Synthesis of PBG 2 is shown in Scheme 2. 3 was synthesized according to a previous report [15]. 3 and di- $n$-butyltin dilaurate was dissolved in benzene and the corresuponding isocyanete in benzene was dropped at $70{ }^{\circ} \mathrm{C}$. After finising drop, reaction mixture was stirred for $2 \mathrm{~h}$. The solution was concentrated in an evaporator to remove benzene. The residue was separated by chromatography on silica gel. Evapolation of remained eluent gave white solids. White solids were dissolved in small amount of THF. The solution reprecipitated with hexane to give white solids (PBG 2) in a $96 \%$ yield.

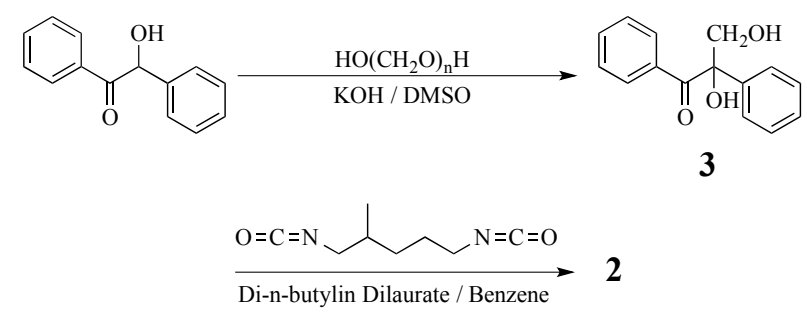

Scheme 2. Synthesis of PBG 2

2: ${ }^{1} \mathrm{H}$ NMR (500 MHz, $\mathrm{CDCl}_{3}$ ): $\delta$ (ppm) $0.8 \sim 1.3$ $\left(\mathrm{m}, 8 \mathrm{H},-\mathrm{C}_{2^{-}},>\mathrm{C} \underline{\mathrm{H}}-,-\mathrm{C}_{3}\right), \quad 2.9 \sim 3.1(\mathrm{~m}, 4 \mathrm{H}$, $\left.-\mathrm{CH}_{2}-\mathrm{NHCO}-\right), 4.5 \sim 5.0(\mathrm{~m}, 8 \mathrm{H},-\mathrm{OH},-\mathrm{N} \underline{\mathrm{H}}-$, C-C $\left.\underline{\mathrm{H}}_{2}\right), 7.2 \sim 7.9(\mathrm{~m}, 20 \mathrm{H}, \mathrm{Ar} \underline{\mathrm{H}})$. IR $\left(\mathrm{KBr}, \mathrm{cm}^{-1}\right)$ : $1720(>\mathrm{C}=\mathrm{O}), 2925(\mathrm{C}-\mathrm{H}), 3050(\mathrm{Ar}-\mathrm{H}), 3400$ (O-H). Anal. Found: C, 69.92; H, 6.19; N, 4.29. Calcd for $\mathrm{C}_{30} \mathrm{H}_{40} \mathrm{~N}_{2} \mathrm{O}_{8}$ : C, 69.64; H,6.25; N,4.50. $\mathrm{UV}\left(\mathrm{CH}_{3} \mathrm{CN}\right): \varepsilon_{254}=10500$.

\section{Synthesis of poly[(methacryloxypropyl) silsesquioxane] (MA-PS)}

MA-PS is a polymer as a result of hydrolytic polycondensation of 3-methacryloxypropyl -trimethoxysilane (MAS). MA-PS was synthesized according to a previous report [16].

\section{2. Photosensitivity determination}

The solutions were prepared by dissolving $0.5 \mathrm{~g}$ of MA-PS $\left(M_{\mathrm{w}}=2000, M_{\mathrm{w}} / M_{\mathrm{n}}=1.3\right)$ and $2(2.5$, 5.0 , and $10 \mathrm{~mol} \%$ relative to monomer units of MAS) in $0.5 \mathrm{~g}$ of chloroform. The solutions were spin-coated on silicon wafers and baked at 100 ${ }^{\circ} \mathrm{C}$ for $1 \mathrm{~min}$ to give thin films. The films were exposed to $254 \mathrm{~nm}$-light under nitrogen atmosphere.

\section{3. Physical measurements}

The hardness of films was monitored by the pencil-scratch method based on JIS K5400. The UV curing behavior of films was measured by IR spectroscopy.

\section{Results and discussion}

PBG 2 generates radical and amine by UV-light irradiation. Combination of PBG $\mathbf{2}$ with a radical and a base-sensitive resin MA-PS is expected to form a highly cross-linked polymer. MA-PS is a polymer as a result of hydrolytic polycondensation of MAS, which has methacryloyl groups and residual alkoxysilyl groups. Reaction scheme of PBG 2 and MA-PS is shown in Scheme 3.

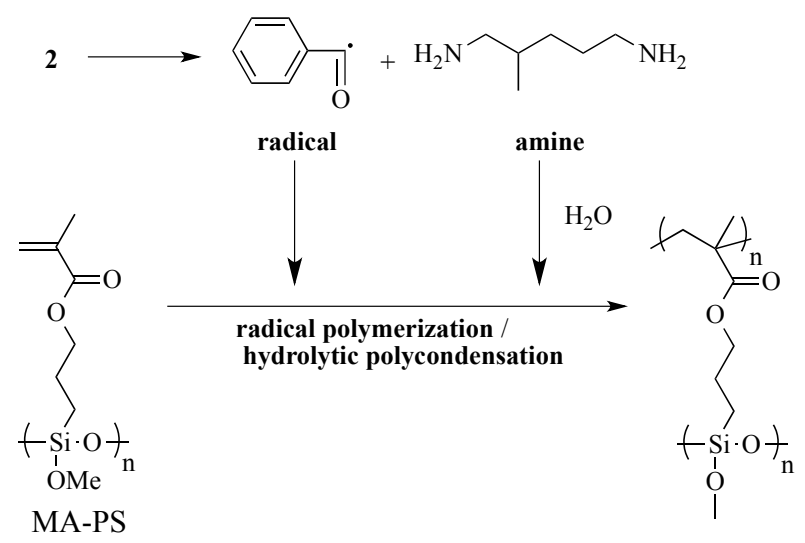

Scheme 3. Application of 2 to hybrid curing system using radical polymerization and hydrolytic polycondensation

Figure 1 shows UV curing behavior of MA-PS films sensitized with $2.5 \sim 10 \mathrm{~mol} \%$ of PBG2. In the case of $10 \mathrm{~mol} \%$, the coating film showed a level of $\mathrm{H}$ at an exposure dose of $1.0 \mathrm{~J} / \mathrm{cm}^{2}$. On the other hand, there were no differences in

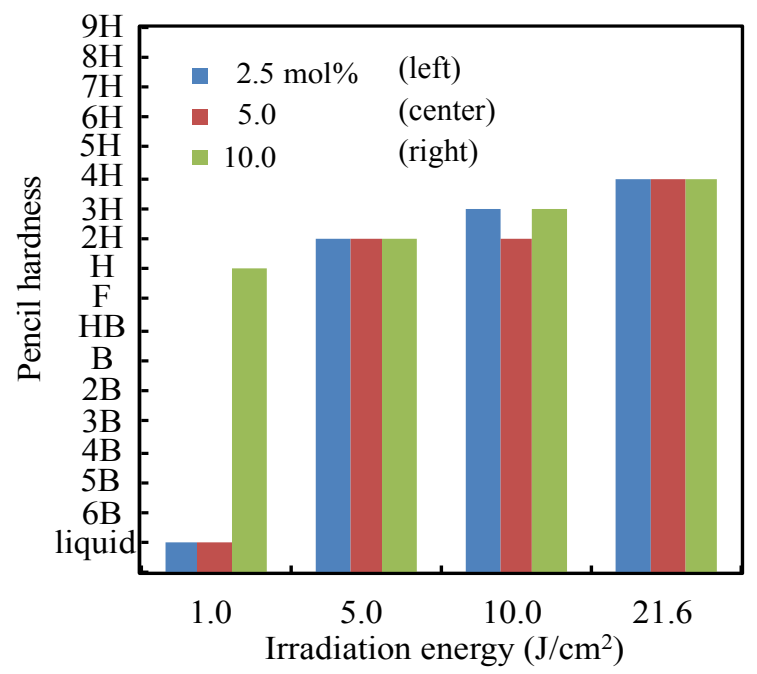

Figure 1. Pencil hardness of MA-PS films containing 2.5, 5.0, and $10.0 \mathrm{~mol} \%$ of PBG 2 after $254 \mathrm{~nm}$-light irradiation. 
pencil hardness, when irradiation energy was more than $5.0 \mathrm{~J} / \mathrm{cm}^{2}$. Practically, we investigated whether radical polymerization and sol-gel reactions progressed by FT-IR spectroscopy. Figure 2 shows the relationship between pencil-hardness and conversion of $\mathrm{C}=\mathrm{CH}_{2}$ and Si-OMe groups. The peaks due to $\mathrm{C}=\mathrm{CH}_{2}$ and $\mathrm{Si}-\mathrm{OMe}$ groups decreased in parallel and pencil hardness increased with the increment of UV exposure doses. This result shows that radical and amine generated from $\mathbf{2}$ caused cross-linking reactions of radical polymerization and hydrolytic polycondensation.

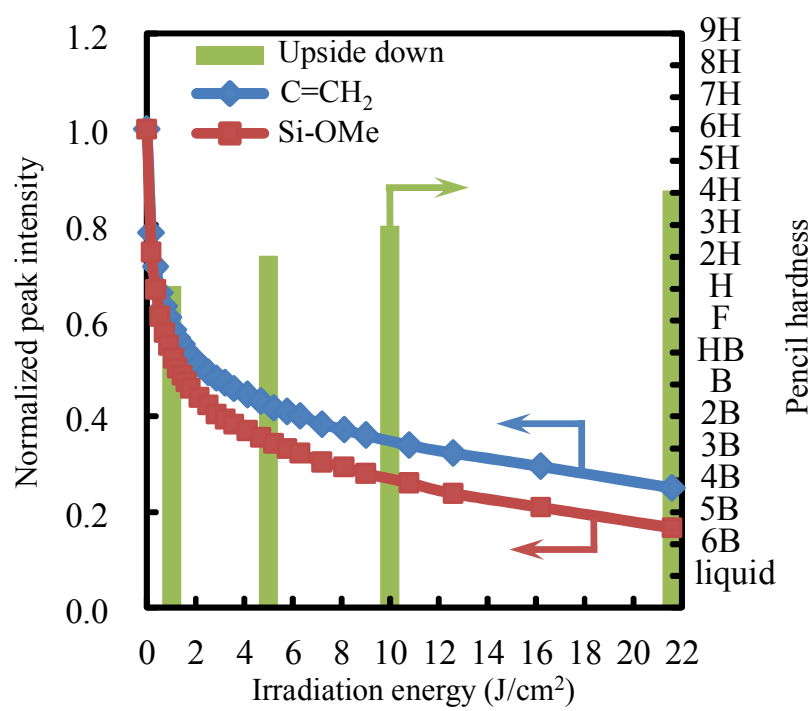

Figure 2. Relationship between peak intensity of $\mathrm{C}=\mathrm{CH}_{2}$ and $\mathrm{Si}-\mathrm{OMe}$ groups of MA-PS and pencil hardness of MA-PS films doped with $10 \mathrm{~mol} \%$ of $\mathbf{2}$ after $254 \mathrm{~nm}$-light irradiation.

In conclusion, we developed PBG 2 that generates radical and primary amine by UV irradiation. PBG 2 worked effectively for radical polymerization of methacrylate groups and base-catalyzed cross-linking reactions of alkoxysilyl groups in MA-PS.

\section{References}

1. H. Ito, Adv. Polym. Sci., 172 (2005) 37.

2. S. Sepeur, N. Kunze, B. Werner, H. Schmidt, Thin Solid Films, 351 (1999) 216.

3. T. Scherzer, U. Decker, Vib. Spect., 19 (1999) 385.

4. T. Scherzer, A. Tauber, R. Mehnert, Vib. Spect., 29 (2002) 125.

5. C. Kutal, C. G. Willson, J. Electronchem. Soc., 134 (1987) 2280.

6. K-I. Ito, M. Nishimura, M. Sashio, M. Tsunooka, J. Polym. Sci. Part A: Polym.Chem., 32 (1994) 2177.

7. J. F. Cameron, J. M. J. Frechet, J. Org. Chem., 55 (1990) 5919.

8. J. F. Cameron, J. M. J. Fréchet, J. Am. Chem. Soc., 113 (1991) 4303.

9. J. F. Cameron, C. G. Willson, J. M. J. Fréchet, J. Am. Chem. Soc., 118 (1996) 12925.

10. A. Blanc, C. G. Bouchet. J. Am. Chem. Soc., 126 (2004) 7174.

11. X. Sun, J. P. Gao, Z. Y. Wang, J. Am. Chem. Soc., 2008, 130, 8130.

12. K. Arimitsu, R. Endo, Chem. Mat., 25 (2013) 4461.

13. A. Chemtob, D. L. Versace, C. Belon, C. C. Barghorn, S. Rigolet, Macromolecules, 41 (2008) 7390-7398.

14. H. Inoue, K. Matsukawa, Y. Tanaka, N. Nishioka. J. Photopolym. Sci. Technol., 12 (1999) 129-132.

15. N. Ishikawa, K, Arimitsu, T. Gunji, Y. Abe, Chem. Lett., doi:10.1246.

16. T. Gunji, Y. Makabe, N. Takamura, Y. Abe, Appl. Organometal. Chem., 15 (2001) 683. 